\title{
Fertilization peculiarities of human oocytes during assisted reproduction according to their morphological features and patients' ovarian reserve
}

\begin{abstract}
Aim: The current study represents results from retrospective and prospective researches on the particularities of fertilization of human oocytes during assisted reproduction regarding their morphological features as well as patients` ovarian reserve.

Materials and methods: The investigation involved 3038 oocytes from 419 patients who had participated in a program for infertility treatment by IVF/ICSI from February 2011 till February 2014, 72 patients had reduced ovarian reserve and 347 had normal ovarian reserve.

Results: Our study found out that the patients with normal and low ovarian reserve had statistically significant differences in relation to percentages of fertilized oocytes with 2 pronuclei $(\mathrm{p}<0.05)-84.33 \%$ and $76.87 \%$, respectively. A statistically significant difference $(\mathrm{p}<0.0001)$ was found regarding zygotes, derived from oocytes with different morphological features in both studied groups of patients with apparent prevalence of the zygotes derived from non-defective oocytes in patients with normal ovarian reserve $(81,18 \%)$ in comparison with patients with low ovarian reserve $(48.67 \%)$. A tendency of reducing the percentage of zygotes obtained from normal oocytes was observed with aging of patients with low ovarian reserve in comparison with patients with normal ovarian reserve where a statistically significant difference was not observed.
\end{abstract}

Conclusion: The condition of the patients' ovarian reserve stands out to be a major factor influencing oocytes fertilization rates during assisted reproduction.

Keywords: IVF, ICSI, fertilization rate, oocyte quality, ovarian reserve, normal responders, low responders
Volume 6 Issue I - 2019

\author{
Gergana Ingilizova \\ Vita Multidisciplinary Hospital for Active Treatment, Sofia, \\ Bulgaria
}

Correspondence: Gergana Ingilizova, "Vita" Multidisciplinary Hospital for Active Treatment, 10 Filip Kutev str, Sofia I407, Bulgaria,Email gergana.ingilizova@gmail.com

Received: December 16, 2018 | Published: January 04, 2019

\section{Introduction}

Every successful cycle of assisted reproduction via "out-of-body" fertilization - in vitro fertilization (IVF) or intracytoplasmic sperm injection (ICSI) is a result of a sequence of correctly run biological events. Fertilization is a key moment with crucial significance for such a cycle. Fertilization rates can be influenced by numerous factors such as the morphological and functional characteristics of the oocytes, laboratory methods and the techniques of insemination being used, cell culture conditions, patients` ovarian reserve and age, their hormonal status etc.

The decreased ovarian reserve is a condition of lowered fertility which is characterized by a low number of oocytes in the ovary and decreased oogenesis due to age, congenital, iatrogenic and idiopathic factors. ${ }^{1,2}$ The results of the treatment procedures by in vitro fertilization in these patients are related to low number of follicles after controlled ovarian hyperstimulation $(\mathrm{COH})$, a low number of aspirated oocytes with worse morphological features, a lower fertilization rate and consequently a lower rate of achieved pregnancies.

According to morphological criteria, human oocytes are classified as: 1) normal; 2) oocytes with extracytoplasmic abnormalities; 3) oocytes with intracytoplasmic abnormalities; 4) oocytes with abnormalities of size and shape; and 5) oocytes with multiple abnormalities. ${ }^{3}$ Some studies have revealed that embryos derived from normal oocytes have the highest potential for implantation in the uterus. ${ }^{4,5}$
In the literature data the patients' age is pointed out as a basic marker with prognostic value regarding to the oocyte quality. ${ }^{6,7}$ It is believed that the decrease in the percentage of the achieved pregnancies with aging is due to reduction of the ovarian reserve and deterioration of the morphological features of the oocytes, respectively fertilization and embryos of good quality rates. ${ }^{8}$

\section{Materials and methods}

This study represents the results from a retrospective and prospective analysis on 3038 oocytes from 419 patients that have taken part in a program for infertility treatment by in vitro fertilization in the period from February 2011 till February 2014 in "Vita" Multidisciplinary Hospital for Active Treatment - Sofia, First Specialized Obstetrics and Gynecology Hospital for Active Treatment "St. Sofia" - Sofia, and Medical Center for Assisted Reproduction" Varna “ - Varna, Bulgaria. 184 of the oocytes were obtained as a result of 72 treatment cycles by IVF / ICSI in patients with low ovarian reserve. This group included patients meeting at least two of the following criteria: FSH levels on the third day of the menstrual cycle $>10 \mathrm{mIU} / \mathrm{ml}$, Anti-Müllerian hormone (AMH) levels $<1.2 \mathrm{ng} / \mathrm{ml}$, number of antral follicles $\leq 7$, age $\geq 40$ years, and previous unsatisfactory reply to $\mathrm{COH}$. The remaining 2854 oocytes originated from 347 patients with normal $\mathrm{COH}$ response. All oocytes were subjected to microscopic analysis to determine maturity and quality assessment according to their morphological features. ${ }^{9}$ 


\section{Results and discussion}

According to the fertilization of the oocytes and the number of observed pronuclei $(\mathrm{PN})$ the fertilization rates in patients with low and normal ovarian reserve were estimated and compared (Table 1).

There was a statistically significant difference regarding the percentage of normally fertilized oocytes (with $2 \mathrm{PN}$ ) among the patients in both groups $(\mathrm{p}<0.05)$ at $76.87 \%$ in low responders versus $84.33 \%$ in normal responders, as well as the percentage of non-fertilized zygotes $(0 \mathrm{PN})(\mathrm{p}<0.05)$ at $21.77 \%$ versus $13.61 \%$, respectively. Regarding the zygotes with $3 \mathrm{PN}$ and $1 \mathrm{PN}$ a statistically significant difference was not found $(\mathrm{p}>0.05)$.

When comparing data by age group, where applicable, no statistically significant difference was observed regarding the percentages of zygotes with 2 PN ( $p>0.05)$. A statistically significant difference was also not found with respect to the percentages of the zygotes with $3 \mathrm{PN}, 1 \mathrm{PN}$ and the non-fertilized oocytes (0 PN) among the distinct age groups. The results show that the statistically significant difference in fertilization rates only occurs when comparing the two groups of patients as a whole, but it is not detectable by age group comparisons. This means that the fourth and fifth age groups in patients with low ovarian reserve have a significant effect on the overall results for the group.

Depending on the morphological characteristics of the oocytes, the percentages of the zygotes obtained in the two groups of patients with normal and decreased ovarian reserve were compared to the Fisher's exact test and a statistically significant difference $(p<0.0001)$ was found with apparent prevalence of zygotes obtained from oocytes without defects in patients with normal ovarian reserve $(81.18 \%)$ compared to patients with decreased ovarian reserve $(48,67 \%)$ (Table 2) (Figure 1).

Table I Percentage ratio of zygotes / oocytes in both groups depending on fertilization and number of pronuclei

\begin{tabular}{|c|c|c|c|c|c|c|c|c|}
\hline \multirow[t]{2}{*}{ Group } & \multirow[t]{2}{*}{ Age group } & \multirow[t]{2}{*}{$\begin{array}{l}\text { Number of } \\
\text { inseminated oocytes }\end{array}$} & \multicolumn{2}{|c|}{ Zygotes with 2 PN } & \multicolumn{2}{|c|}{$\begin{array}{l}\text { Zygotes with } \\
3 \text { PN, } 1 \text { PN }\end{array}$} & \multicolumn{2}{|c|}{ Zygotes with 0 PN } \\
\hline & & & $\mathbf{n}$ & $\%$ & $\mathbf{n}$ & $\%$ & $\mathbf{n}$ & $\%$ \\
\hline \multirow[t]{4}{*}{ Normal responders } & 1 ( $<30$ years $)$ & 591 & 508 & 85.96 & 6 & 1.02 & 77 & 13.03 \\
\hline & 2 (31-35 years) & 1540 & 1304 & 84.68 & 37 & 2.40 & 199 & 12.92 \\
\hline & 3 (36-40 years) & 352 & 282 & 80.11 & 8 & 2.27 & 62 & 17.61 \\
\hline & Total & 2483 & 2094 & 84.33 & 51 & 2.05 & 338 & 13.61 \\
\hline \multirow[t]{6}{*}{ Low responders } & 1 (<30 years $)$ & 7 & 6 & 85.71 & 1 & 14.29 & 0 & 0 \\
\hline & 2 (31-35 years) & 45 & 36 & 80.00 & 0 & 0 & 9 & 20 \\
\hline & 3 (36- 40 years) & 61 & 47 & 77.05 & 1 & 1.64 & 13 & 21.31 \\
\hline & $4(41-45$ years $)$ & 31 & 22 & 70.97 & 0 & 0 & 9 & 29.03 \\
\hline & 5 (>45 years) & 3 & 2 & 66.67 & 0 & 0 & 1 & 33.33 \\
\hline & Total & 147 & 113 & 76.87 & 2 & 1.36 & 32 & 21.77 \\
\hline
\end{tabular}

Table 2 Summarized statistical data on the zygotes obtained, depending on the morphological features of the oocytes

\begin{tabular}{|c|c|c|c|c|c|c|c|c|c|c|}
\hline \multirow[t]{3}{*}{ Group } & \multirow[t]{3}{*}{ Age group } & \multirow{3}{*}{$\begin{array}{l}\text { Number of } \\
\text { zygotes with } 2 \text { PN } \\
\text { Number }\end{array}$} & \multicolumn{8}{|c|}{ Zygote obtained from oocytes with } \\
\hline & & & \multicolumn{2}{|c|}{ Normal morphology } & \multicolumn{2}{|c|}{$\begin{array}{l}\text { Extracytoplasmic } \\
\text { abnormalities }\end{array}$} & \multicolumn{2}{|c|}{$\begin{array}{l}\text { Intracytoplasmic } \\
\text { abnormalities }\end{array}$} & \multicolumn{2}{|c|}{ Multiple abnormalities } \\
\hline & & & Number & $\%$ & Number & $\%$ & Number & $\%$ & Number & $\%$ \\
\hline \multirow[t]{4}{*}{$\begin{array}{l}\text { Normal } \\
\text { responders }\end{array}$} & 1 (<30 years) & 508 & 435 & $85.63 \%$ & 28 & $5.51 \%$ & 11 & $2.17 \%$ & 34 & $6.69 \%$ \\
\hline & 2 ( $31-35$ years) & 1304 & 1050 & $80.52 \%$ & 94 & $7.21 \%$ & 47 & $3.60 \%$ & 113 & $8.67 \%$ \\
\hline & $3(36-40$ years $)$ & 282 & 215 & $76.24 \%$ & 16 & $5.67 \%$ & 9 & $3.19 \%$ & 42 & $14.89 \%$ \\
\hline & Total & 2094 & 1700 & $81.18 \%$ & 138 & $6.59 \%$ & 67 & $3.20 \%$ & 189 & $9.03 \%$ \\
\hline \multirow{6}{*}{$\begin{array}{l}\text { Low } \\
\text { responders }\end{array}$} & 1 (<30 years $)$ & 6 & 5 & $83.33 \%$ & 0 & $0.00 \%$ & 1 & $16.67 \%$ & 0 & $0.00 \%$ \\
\hline & 2 (31-35 years) & 36 & 26 & $72.22 \%$ & 4 & $11.11 \%$ & 3 & $8.33 \%$ & 3 & $8.33 \%$ \\
\hline & 3 (36-40 years) & 47 & 19 & $40.43 \%$ & 9 & $19.15 \%$ & 4 & $8.51 \%$ & 15 & $31.91 \%$ \\
\hline & 4 ( $41-45$ years $)$ & 22 & 5 & $22.73 \%$ & 1 & $4.55 \%$ & 1 & $4.55 \%$ & 15 & $68.18 \%$ \\
\hline & 5 ( $>45$ years $)$ & 2 & 0 & $0.00 \%$ & 0 & $0.00 \%$ & 0 & $0.00 \%$ & 2 & $100.00 \%$ \\
\hline & Total & 113 & 55 & $48.67 \%$ & 14 & $12.39 \%$ & 9 & $7.96 \%$ & 35 & $30.97 \%$ \\
\hline
\end{tabular}




\section{Zygotes derived from oocytes with:}

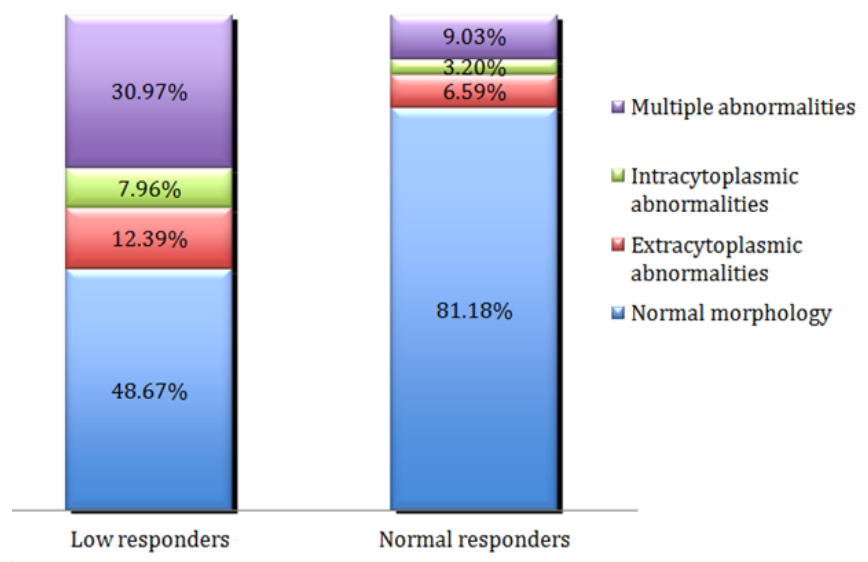

Figure I Percentage ratio of the zygotes obtained in relation to the morphological features of the oocytes in patients with low and normal ovarian reserve.

Regarding the percentages of zygotes obtained from oocytes with different morphological features, a statistically significant difference was found between them in patients with low ovarian reserve $(p<0.0001)$. Table $2 \&$ Figure 1 show a significant predominance of the percentages of zygotes derived from oocytes with normal morphology (48.67\%) and oocytes with multiple defects (30.97\%) compared to percentages of zygotes derived from oocytes with intracytoplasmic $(12.39 \%)$ and extracytoplasmic defects $(7.96 \%)$. It is clear that the significantly higher percentage of embryos obtained from oocytes with multiple defects is due to the fact that most of the aspirated oocytes in these patients exhibited more than one defect. This reduces the percentages of embryos derived from oocytes with extracytoplasmic and intracytoplasmic defects, as only oocytes exhibiting a single defect are attributed to these groups. Therefore the high percentage of zygotes obtained from oocytes with multiple defects is not due to higher fertility potential but to their predominance in patients with low ovarian reserve. Regarding the percentages of zygotes obtained from oocytes with extracytoplasmic and intracytoplasmic abnormalities, Fisher's exact criterion showed no statistically significant difference ( $>0.05$ ), from which a conclusion can be made that fertilization is not associated with the presence of a specific morphological defect. Comparison between the two groups of percentage - those of zygotes obtained from morphologically normal oocytes and those with multiple defects showed a statistically significant difference in the sample population $(\mathrm{p}<0.05)$. The obtained interrelationships can lead to the conclusion that the highest is $1 /$ the percentage of zygotes obtained from oocytes with normal morphology $(48.67 \%)$, followed by $2 /$ the percentage of zygotes obtained from oocytes with multiple defects $(30.97 \%)$ and lastly $3 /$ zygotes obtained from oocytes with extracytoplasmic abnormalities (12.39\%) and oocytes with intracytoplasmic abnormalities (7.96\%), and between the latter two percentages there was no statistically significant difference. However, between 1,2 and 3 , a statistically significant difference $(\mathrm{p}<0.05)$ was observed.

A statistically significant difference between the percentages of zygotes obtained from patients with a normal ovarian reserve $(p<0.0001)$ and those obtained from oocytes with normal morphology, which is logically related to the higher percentage of normal oocytes in this group of patients.
There was a statistically significant difference $(p<0.0001)$ between percentage of oocytes with normal morphology in the distinct age groups in patients with low ovarian reserve, with a tendency to decrease this percentage with the age of $83.33 \%$ in the age group $<30$ years to $0 \%$ in the age group $>45$ years. By comparison the different age groups there was no statistically significant difference between the first two ( $>0.05)$, as well between the last three age groups ( $p>0.05)$ regarding the percentages obtained from normal and defective oocytes. It means that with respect to these variables, the age groups can be divided into two categories - the first category comprising the first and the second age group and the second category comprising the third, fourth and fifth age groups respectively. Both categories were statistically significant different in terms of percentages of zygotes obtained from oocytes with different morphological characteristics $(\mathrm{p}<0.0001)$.

In patients with normal ovarian reserve, there was no statistically significant difference in percentages of embryos derived from normal oocytes between different age groups ( $p>0.05)$.

\section{Conclusion}

Our survey of 419 cycles of in vitro fertilization found that patients with normal and reduced ovarian reserve were statistically different regarding the percentage of fertilized oocytes with $2 \mathrm{PN}(\mathrm{p}<0.05)$ $84.33 \%$ and $76.87 \%$, respectively. In patients with reduced ovarian reserve, the percentages of fertilized normal oocytes and those with multiple defects were significantly higher $(p<0.001)$ than those of fertilized oocytes exhibiting only extracytoplasmic or intracytoplasmic abnormalities. However, in patients with normal ovarian reserve, the percentage of zygotes obtained from normal oocytes prevailed. We also found that in patients with reduced ovarian reserve there was a tendency of decreasing the percentages of zygotes obtained from normal oocytes with age, unlike those with a normal ovarian reserve, where there was no statistically significant difference with respect to these percentages. ${ }^{9}$ Our findings are logically related to the prevalence of oocytes with certain morphological peculiarities in the respective groups of patients and confirm the literature data showing a decrease in fertility rates with increasing age of the patients, depletion of ovarian reserve and deterioration of morphological characteristics of oocytes.

\section{Acknowledgments}

None.

\section{Conflicts of interest}

The authors declare there is no conflicts of interest.

\section{References}

1. Broekmans FJ, Knauff EA, te Velde ER, et al. Female reproductive ageing: current knowledge and future trends. Trends Endocrinol Metab. 2007;18(2):58-65.

2. Ottolenghi C, Uda M, Hamatani T, et al. Aging of oocyte, ovary, and human reproduction. Ann N Y Acad Sci. 2004;1034:117-131.

3. Lasienë K, Vitkus A, Valanèiûtë A, et al. Morphological criteria of oocyte quality. Medicina (Kaunas). 2009;45(7):509-515.

4. Balaban B, Urman B. Effect of oocyte morphology on embryo development and implantation. Reprod Biomed Online. 2006;12(5):608615. 
5. Serhal PF, Ranieri DM, Kinis A, et al. Oocyte morphology predict outcome of intracytoplasmic sperm injection. Hum Reprod. 1997;12(6):1267-1270.

6. Toner JP. Ovarian reserve, female age and the chance for successful pregnancy. Minerva Ginecol. 2003;55(5):399-406.

7. Vollenhofen B, Hunt S. Ovarian agingand the impact on female fertility. F1000Res.
8. Thum, MY, Abdalla HI, Taylor D. Relationship between women's age and basal follicle-stimulating hormone levels with aneuploidy risk in in vitro fertilization treatment. Fertil Steril. 2008;90(2):315-321.

9. Ingilizova G. Biological aspects and prognostic criteria for evaluation of oocytes and preimplantation embryos in patients with low ovarian reserve. Varna: Doctoral Thesis; 2016. 